\title{
APLIKASI SISTEM INFORMASI GEOGRAFIS UNTUK PENGEMBANGAN KAWASAN STRATEGIS PARIWISATA PANTAI BILATO DI KABUPATEN GORONTALO Geographic Information System Application for Strategic Tourism Development Areas of Bilato Beach in Gorontalo District
}

\author{
Elpin Ibrahim ${ }^{1}$, Ivan Taslim², Ahmad Syamsu Rijal ${ }^{3}$ \\ ${ }^{1}$ Sarjana Program studi Geografi Universitas Muhammadiyah Gorontalo, Indonesia \\ ${ }^{2,3}$ Program studi Geografi Universitas Muhammadiyah Gorontalo, Indonesia \\ Korespondensi: elpinibrahim@gmail.com
}

DOI: http://dx.doi.org/10.31314/jsig.v1i1.91

\begin{abstract}
This study aims to create a concept or strategy for the development of Strategic Tourism Area of Bilato Beach located in Gorontalo Regency Gorontalo Province. The planning strategy for the development of Bilato Beach Strategic Area in this research is based on the questionnaire and interview method with the field survey. The results of the interview will be processed using SWOT analysis which further utilizes Geographic Information System (GIS) application for mapping of tourism development of Bilato Beach. In the result of observation at research location and interview (questionnaire) processed with SWOT approach obtained information about research location, such as white sand along the coastal landscape with the calm sea (Strengths). It's just that as a tourist attraction Bilato Beach has lack of adequate facilities, lack of government attention to the manager both in terms of financial aid and tourism publication (Weaknesses). In terms of Opportunities, Bilato Beach can be a source of income and business community, it is also supported by the terms of affordability/accessibility is quite easy. However, Bilato Beach as a tourist spot also has threats such as community activities and visitors that can be damage the natural habitat at the research location and also the many tourist attractions that make the competition in attracting the tourists. The conclusion of this SWOT analysis result is that Bilato Beach which has been designated as Tourism Strategic Area in Gorontalo Regency according to Province Regulation of Gorontalo Regency No. 4, 2011 still has many shortcomings in terms of tourism facilities and government attention in terms of publication.
\end{abstract}

Keywords: tourism, strategic development, gis, swot analysis, bilato beach, gorontalo

\begin{abstract}
Abstrak - Penelitian ini bertujuan untuk membuat konsep atau strategi pengembangan Kawasan Strategis Pariwisata Pantai Bilato yang berada di Kabupaten Gorontalo. Strategi yang digunakan pada penelitian ini berdasarkan metode wawancara dan survai lapangan. Hasil dari wawancara akan diolah menggunakan analisis SWOT yang selanjutnya memanfaatkan aplikasi Sistem Informasi Geografis (SIG) untuk pemetaan pengembangan wisata Pantai Bilato. Pada hasil observasi di lokasi penelitian dan wawancara (kuisioner) yang diolah dengan pendekatan SWOT diperoleh informasi tentang lokasi penelitian, diantaranya adalah pasir putih sepanjang bentang alam pantai dengan laut yang tenang (Kekuatan). Hanya saja sebagai tempat wisata Pantai Bilato memiliki kekurangan dari segi fasilitas yang memadai, tidak adanya perhatian pemerintah terhadap pengelola baik dari segi bantuan dana maupun publikasi wisata (Kelemahan). Dari segi Peluang, Pantai Bilato bisa menjadi sumber pendapatan dan usaha masyarakat, hal ini juga didukung oleh segi keterjangkauan yang cukup mudah. Meski demikian Pantai Bilato sebagai tempat wisata juga mempunyai Ancaman seperti aktifitas masyarakat dan pengunjung yang dapat merusak habitat alami di lokasi penelitian dan juga banyaknya tempat wisata yang menjadikan persaingan dalam menarik minat para wisatawan. Kesimpulan dari hasil analisis SWOT ini adalah bahwa Pantai Bilato yang sudah ditetapkan sebagai Kawasan Strategis Pariwisata di Kabupaten Gorontalo menurut PERDA Provinsi Gorontalo No. 4 Tahun 2011 masih memiliki banyak kekurangan dari segi fasilitas wisata dan perhatian pemerintah dalam hal publikasi.
\end{abstract}

Kata kunci: pariwisata, strategi pengembangan, sig, analisis swot, pantai bilato, gorontalo 


\section{PENDAHULUAN}

Kawasan Strategis Pariwisata adalah kawasan yang memiliki fungsi utama pariwisata atau memiliki potensi untuk pengembangan pariwisata yang mempunyai pengaruh penting dalam satu atau lebih aspek seperti yang termuat dalam Undang-Undang No. 10 Tahun 2009. Pariwisata memiliki peran yang besar dalam pembangunan nasional, karena selain menghasilkan pendapatan daerah, juga sekaligus sebagai penghasil devisa negara. Sektor pariwisata berkaitan erat dengan penanaman modal asing, termasuk mereka yang berhubungan bisnis dengan Indonesia (Rani, 2014). Sumberdaya dan potensi pesisir di Indonesia sangat besar dan belum sepenuhnya di manfaatkan menjadi objek daya tarik wisata. Hal tersebut menunjukan bahwa kawasan pantai Indonesia dapat menjadi sumber daya ekonomi dan pesona tersendiri (Kurniawan, et al., 2011), seperti halnya di Kabupaten Gorontalo yang merupakan salahsatu wilayah yang didominasi oleh bentanglahan pesisir.

Daerah Kabupaten Gorontalo memiliki aset pariwisata yang terdiri dari 8 buah obyek wisata alam, 2 buah obyek wisata sejarah budaya dan 2 buah obyek wisata buatan. Salahsatu obyek wisata alam tersebut adalah Pantai Bilato yang merupakan kawasan strategis pariwisata menurut Perturan Daerah Provinsi Gorontalo No. 4 Tahun 2011. Letaknya di Desa Taulaa Kecamatan Bilato yang dahulunya termasuk Kecamatan Boliyohuto (Gambar 1). Desa Taulaa merupakan salahsatu desa kedua terbesar di Kecamatan Bilato setelah Desa Bilato yaitu dengan luas $18.27 \mathrm{~km} 2$. Desa Taulaa memiliki morfologi yang bervariasi, mulai dari dataran rendah sampai dataran tinggi yakni $11 \mathrm{~km} 2$ dan pegunungan $41 \mathrm{~km} 2$ (BPS Kab. Gorontalo, 2016). Desa Taulaa terletak di antara $0^{\circ} 29.942^{\prime} \mathrm{LU}$ dan $122^{\circ} 41.223^{\prime}$ BT. Desa ini terdiri atas dua dusun yaitu Dusun I dan Dusun II. Secara administrasi desa ini berbatasan dengan Desa Ilomata bagian Utara, Desa Pelehu Bagian barat, Desa Huwongo Kec. Biluhu bagian Timur dan Teluk Tomini bagian Selatan. Jumlah penduduk secara keseluruhan adalah 830 jiwa yang terdiri dari 432 jiwa laki-laki dan 398 jiwa perempuan, serta terdiri atas 208 kepala keluarga. Luas area atau area pemukiman di Desa Taulaa adalah 36 ha, perkebunan 16 ha, pekarangan 50 ha, perkantoran 1 ha, sarana umum lainnya 4 ha, hutan rakyat 293 ha, area penggunaan lainnya 64 ha, luas hutan 4960 ha, serta perkebunan 2 ha (BPS, 2016).

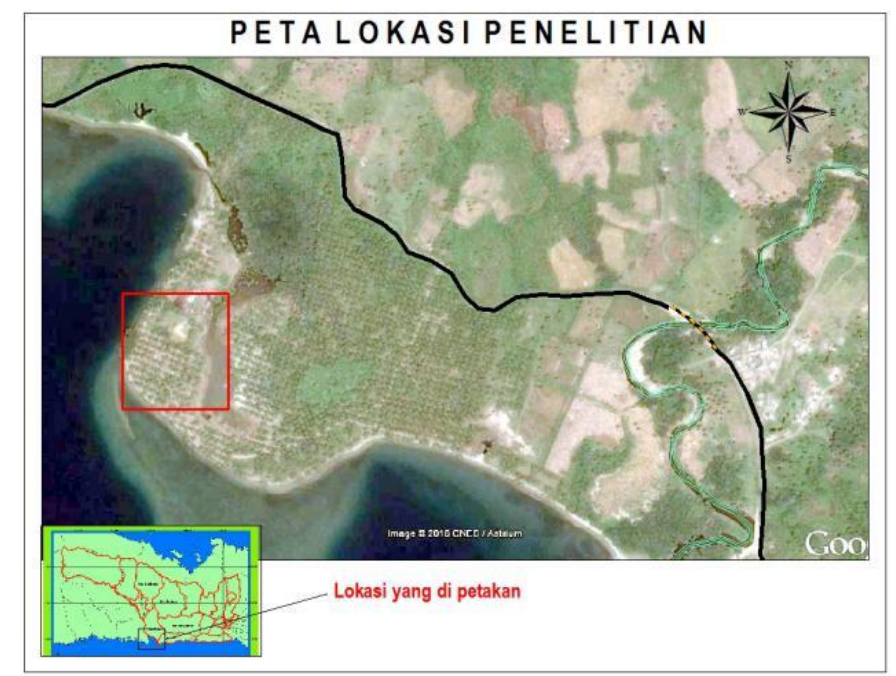

Gambar 1. Peta Lokasi Pantai Bilato (sumber: GoogleEarth,2016)

Pantai Bilato memiliki pantai dengan hamparan pasir putih yang disekitarnya ditumbuhi tanaman produksi tahunan yaitu kelapa. Selain itu pantai ini mempunyai ciri khas laut yang jernih yang tidak bergelombang sehingga cukup aman bagi pengunjung. Pantai Bilato sudah memiliki beberapa daya tarik sebagai tempat wisata, hanya saja terdapat beberapa kekurangan seperti dari segi fasilitas dan aksesibilitas yang memadai untuk menarik wisatawan. Sebagai salahsatu wilayah yang termasuk dalam kawasan strategis pariwisata di Kab. Gorontalo, tentu diperlukan sebuah konsep pengembangan oleh Pemerintah setempat untuk dapat menarik wisatawan yang sekiranya akan menjadi salahsatu pendapatan daerah dalam bidang pariwisata. 


\section{METODE DAN DATA}

Konsep atau strategi pengembangan Pantai Bilato, dilakukan dengan melakukan survei lapangan, yaitu melakukan penilaian terhadap akses lokasi, fasilitas, serta objek daya tarik wisata yang ada. Selain itu dilakukan juga validasi wawancara dengan metode kuisioner yang melibatkan pengunjung, masyarakat setempat serta pemerintah daerah sebagai pengelola tempat wisata. Data yang didapatkan akan diolah dan dianalisis dengan menggunakan metode SWOT yang merupakan sebuah metode perencanaan strategis yang digunakan untuk mengevaluasi kekuatan (strengths), kelemahan (weaknesses), peluang (opportunities), dan ancaman (threats) untuk suatu spekulasi bisnis. Alat dan bahan yang digunakan dalam penelitian adalah Global Positioning System (GPS) tipe Oregon 650 yang digunakan untuk mengetahui posisi geografis, kamera untuk dokumentasi di lapangan, dan alat tulis menulis. Adapun bahan yang digunakan adalah perangkat kuisioner untuk wawancara serta foto citra yang dari Google Earth untuk membuat peta lokasi penelitian dan analisis pengembangan Pantai Bilato.

Penelitian di obyek wisata Pantai Bilato di lakukan untuk menyusun konsep pengembangan pantai sebagai kawasan strategis pariwisata dengan menggunakan metode analisis spasial berbasis SIG yang di lengkapi data observasi dan wawancara. Pengumpulan data melalui observasi dilakukan dengan mengamati obyek wisata menggunakan kamera yang meliputi:

1. Atraksi wisata, yakni semua data yang berkaitan dengan potensi alam di Pantai Bilato.

2. Amenitas, adalah data yang berupa fasilitas yang ada seperti cottage, warung, WC umum, air bersih dan lain sebagainya dan,

3. Aksesibilitas, yaitu data yang berkaitan dengan kemudahan menjangkau obyek wisata.

Wawancara merupakan teknik yang digunakan untuk mengumpulkan data sekunder berupa informasi pengunjung wisata Pantai Bilato, adat istiadat dan peninggalan-peninggalan bersejarah yang dapat diperoleh dari instansi terkait seperti Dinas Pariwisata, pengelola wisata dan lembaga masyarakat. Data yang di peroleh baik data primer maupun data sekunder akan dianalisis secara deskriptif kualitatif yang diimplementasikan secara spasial. Analisis deskriptif kualitatif bertujuan untuk mendeskripsikan apa saja yang saat ini berlaku, di dalamnya terdapat upaya mendeskripsikan, mencatat, dan menginterpretasikan kondisi dan situasi yang ada secara benar, sedangkan dalam implementasinya secara spasial dengan menggunakan perangakat SIG untuk mempermudah pembuatan jalur aksesibilitas menuju Pantai Bilato, konsep fasilitas dan sebagainya. Dengan demikian hasil dari penelitian ini merupakan strategi dan upaya perencanaan yang dapat digunakan pemerintah dalam mengelola kawasan strategis pariwisata Pantai Bilato agar dapat menjadi lebih baik.

\section{HASIL DAN PEMBAHASAN}

Atraksi Pantai Bilato diantaranya yaitu memiliki keindahan laut dan pemandangan sekitar yang juga menarik. Laut biru yang tenang menjadi salah satu keunggulan pantai ini karena sangat aman bagi pengunjung. Selain itu di sepanjang garis pantainya merupakan pasir putih yang melengkapi potensi Pantai Bilato sebagai tempat wisata (Gambar 2). Berdasarkan wawancara dengan masyarakat setempat, bahwa pantai bilato ini merupakan pantai yang sangat strategis dan potensi untuk di jadikan sebagai pelabuhan, karena kapal pesiar sering berlabuh di pantai ini. Hal ini seiring dengan rencana Pemerintah Kabupaten Gorontalo yang saat ini akan menjadikan kawasan Taulaa dan sekitarnya menjadi area pelabuhan terbesar di daerah Kabupaten Gorontalo. Adapun berdasarkan observasi di lapangan, dapat diketahui bahwa penggunaan lahan di Sekitar Pantai Bilato adalah pertanian jagung dan tanaman produksi tahunan yaitu kelapa. Sehingga selain dapat dikembangkan wisata bahari, Pantai Bilato juga berpotensi untuk dikembangkan fasilitas untuk wisata kuliner. 


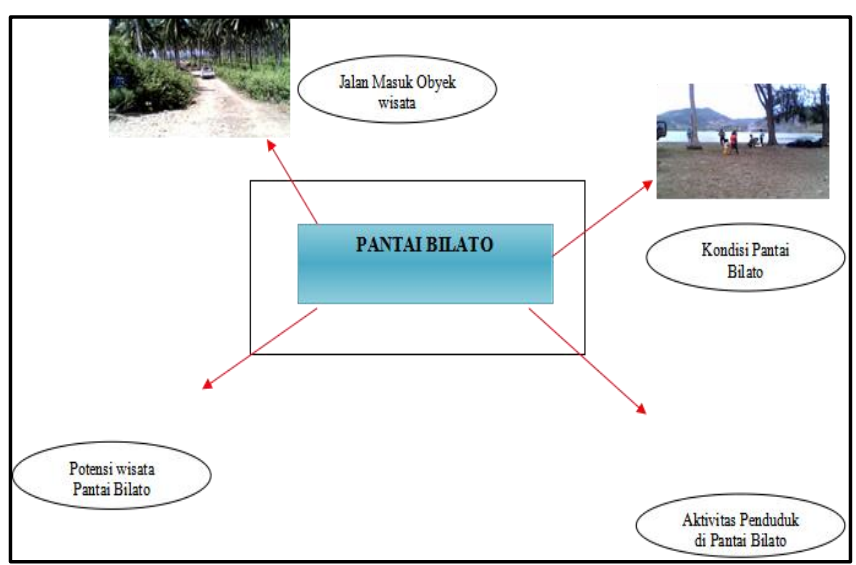

Gambar 2. Potensi Wisata Pantai Bilato (Sumber: Hasil Analisis, 2017)

Pengunjung Pantai Bilato 60\% pada kelompok umur 19-25 tahun, 20\% kelompok umur 26-32 tahun, 15\% kelompok umur 33-39 tahun dan 5\% pada kelompok umur 40-46 tahun. Dari data hasil wawancara dan pengamatan di lapangan seperti yang cantumkan pada Gambar 3, dapat diketahui bahwa pengunjung wisata Pantai Bilato lebih banyak wisatawan berumur 19 sampai dengan wisatawan yang berumur 25 tahun dengan tujuan untuk berlibur dan jalan-jalan sekaligus melakukan penelitian. Hal ini disebabkan oleh keberadaan Pantai Bilato yang cukup jauh dari pusat kabupaten/kota Gorontalo sekitar $62 \mathrm{~km}$ sekitar 2 jam perjalanan menggunakan kendaraan roda empat dan minimnya tempat-tempat peristrahatan untuk para pengunjung.

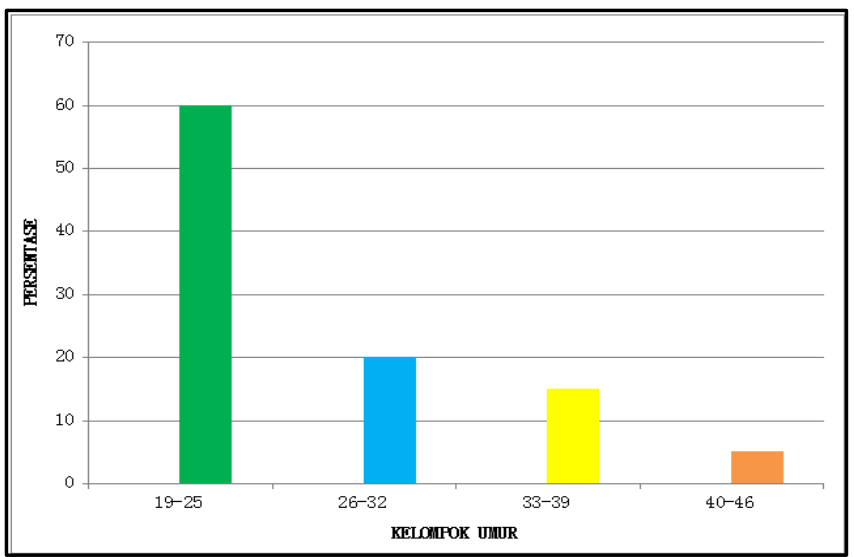

Gambar 3. Diagram karakteristik wisatawan berdasarkan kelompok umur (Sumber: Profil Desa Taulaa, 2017)

Berdasarkan hasil wawancara dengan masyarakat setempat (Gambar 4), diketahui bahwa sebagian besar berpendapat bahwa Pantai Bilato cukup baik jika di lihat dari segi daya tarik wisatanya, namun tak jarang juga masyarakat yang mengatakan Pantai Bilato kurang baik, karena mereka memandang dari segi pengelolaan wisata yang tidak terarah dan tidak berkembang. Wisatawan yang berkunjung ke Pantai Bilato menilai bahwa pantai ini sangat baik dengan 1 responden, 7 responden dengan penilaian baik serta 17 responden menilai Pantai Bilato kurang baik (Gambar 5). Secara umum dapat disimpulkan bahwa keadaan Pantai Bilato perlu untuk dikembangkan. Wisatawan yang berkunjung ke Pantai Bilato belum puas dengan ketersediaan produk wisata terutama pelayanan (amenitas), karena di Pantai Bilato pelayanan dari segi fasilitas wisata tidak memadai bahkan hampir tidak tersedia. Sehingga daya tarik wisata juga harus didukung dengan kebutuhan wisatawan yang berkunjung dari segi pelayanan dan fasilitas. 


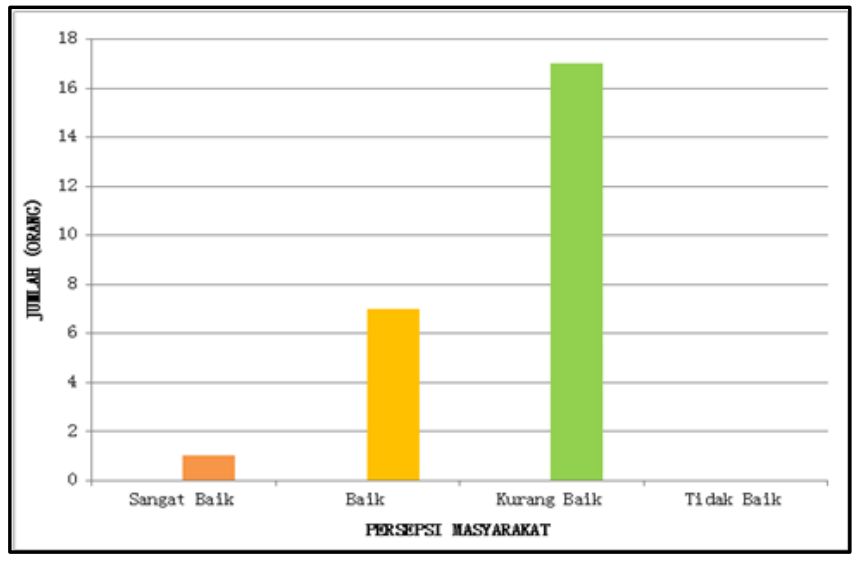

Gambar 4. Persepsi masyarakat tentang Pantai Bilato (Sumber: Hasil Analisis, 2017)

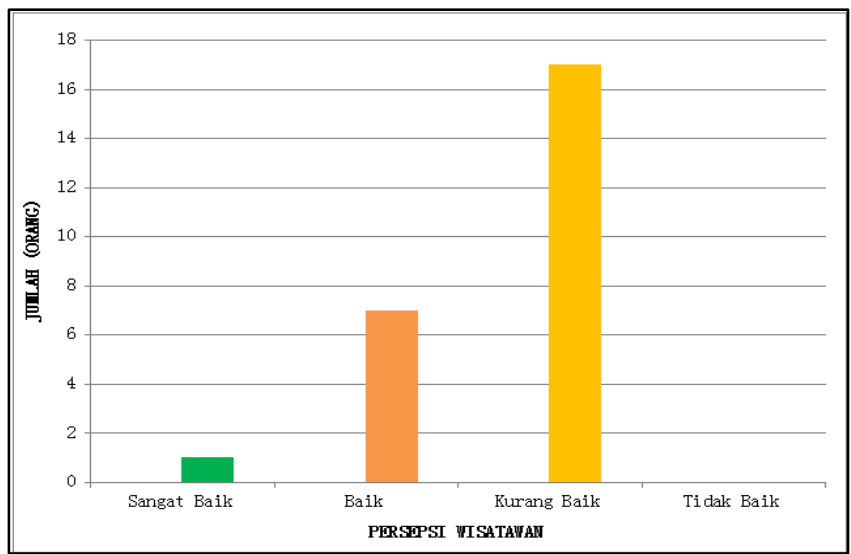

Gambar 5. Persepsi Wisatawan tentang Pantai Bilato (Sumber: Hasil Analisis, 2017)

\section{Strategi pengembangan Pantai Bilato berdasarkan hasil analisis SWOT}

Kondisi Pantai Bilato berdasarkan hasil survei lapangan dan wawancara sangatlah memprihatinkan. Dari segi fasilitas wisata (amenitas) atau semua yang terkait dengan pelayanan baik dari pengelola wisata maupun infrastruktur wisata sangat kurang memadai bagi wisatawan (Gambar 6). Keadaan pantai yang hanya memiliki 1 gazebo dan 1 kamar mandi saat ini sudah rusak sehingga belum mampu menarik minat wisatawan untuk berkunjung, meski dari segi atraksi pantai cukup bervariasi dan menarik. Untuk itulah harus dibuat sebuah strategi pengembangan Pantai Bilato agar lebih menarik perhatian wisatawan (Gambar 7), diantaranya penyediaan spot rekreasi air (berenang dan memancing), fasilitas kamar ganti dan mandi, adanya pusat kuliner dan sentra oleh-oleh, serta sarana tempat parkir, tempat penginapan/cottage, sarana ibadah dan hal-hal lain yang dianggap perlu lainnya. Tidak hanya itu, pemerintah setempat juga harus gencar dalam hal promosi wisata agar dapat menarik minat wisatawan. 


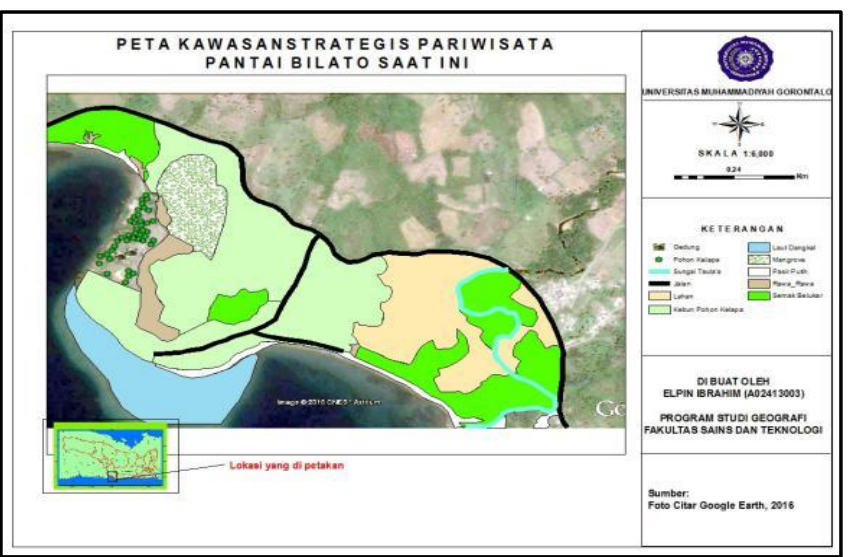

Gambar 6. Peta kawasan strategis pariwisata Pantai Bilato (saat ini)

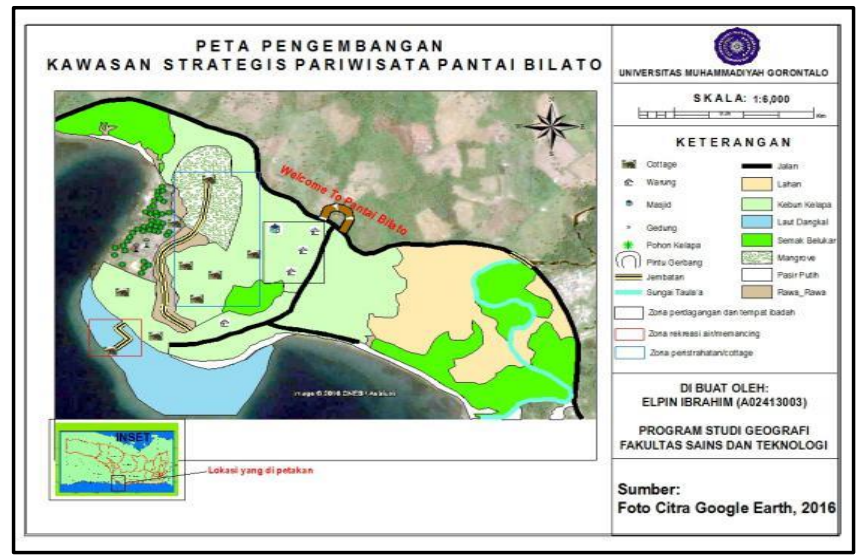

Gambar 7. Peta strategi pengembangan Pantai Bilato (berdasarkan Hasil Analisis. 2017)

\section{KESIMPULAN}

Kawasan Pantai Bilato yang cukup luas dengan daya tarik yang cukup menarik minat wisatawan untuk berkunjung. Untuk itu haruslah ada upaya dari pemrintah setempat dan juga masyarakat untuk membenahi kekurangan yang ada. Pengembangan dan pengelolaan yang baik dapat dilakukan beberapa cara seperti berikut:

1. Promosi dalam rangka menyebarluaskan informasi tentang Pantai Bilato ke media-media sosial dan media cetak (koran, majalah) serta media eletronik (radio dan televisi). Tujuannya untuk memperkenalkan obyek wisata kepada masyarakat luas.

2. Perbaikan Aksesibilitas, Amenitas dan Fasilitas segera mungkin untuk dilakukan, agar dapat menjadi salahsatu tempat berwisata yang menjadi kebanggan tidak hanya buat pemerintah dan masyarakat, tetapi juga Indonesia secara Internasional.

\section{DAFTAR PUSTAKA}

Badan Pusat Statistik (BPS). 2015. Perkembangan Pariwisata Dan Transportasi Nasional

Badan Pusat Statistik (BPS). 2016. Kecamatan Bilato dalam Angka. 2016

Bafdal, N., Amaru, K., Boy, M.P.P. 2011. Sistem Informasi Geografi. Bandung, Jur.TMIP. FTIP. Unpad

Kurniawan, D.T., Armono, Dwito H, dan Mustain, M. 2011. Evaluasi Beach Recreational Index Untuk Pantai Wisata pada Pantai Kenjeran Pantai Delegan, dan Wisata Bahari Lamongan (Jurnal Tugas Akhir)

Maryani, E. 2008. Penataan Ruang Wisata Alam Pantai. Scientific Meeting: Perubahan Iklim Global. Bali 18-19 Maret 2008

Peraturan Daerah Provinsi Gorontalo Nomor 4 Tahun 2011. Rencana Tata Ruang Wilayah Provinsi Gorontalo 2010-2030. Gorontalo.

Profil Desa Taulaa. 2015 
Rani, D.P.M, 2014. Pengembangan Potensi Pariwisata Kabupaten Sumenep, Madura, Jawa Timur (Studi Kasus: Pantai Lombang). Jurnal Politik Muda 3(3)

Rangkuti, F., 2010. Analisis SWOT Teknik Membedah Kasus Bisnis. Jakarta: PT Gramedia Pustaka Utama

Sudana, P. 2013. Strategi Pengembangan Desa Wisata Ekologis Di Desa Belimbing Kecamatan Pupuan Kabupaten Tabanan. Jurnal Analisis Pariwisata 13(1)

Tumimomor, M., Jando, E., Meolbatak, E. 2013. Sistem Informasi Geografis Pariwisata Kota Kupang. Jurnal Nasional Pendidikan Teknik Informatika 1(2)

Undang-undang Republik Indonesia Nomor 10 Tentang Kepariwisataan. 2009. Jakarta

Yoeti, O. 2008. Anatomi Pariwisata. Bandung. Penerbit Angkasa 